\title{
Potential Benefits of Web-based Idea Management System Based on Practical Evidence
}

\author{
Elīna Miķelsone \\ Managament DepartmentBA School of \\ Business and Finance \\ Riga, Latvia \\ mikelsone.elina@gmail.com
}

\author{
Tatjana Volkova \\ Managament Department \\ BA School of Business and Finance \\ Riga, Latvia \\ tatjana.volkova@ba.lv
}

\author{
Elita Lielā \\ Managament Department \\ BA School of Business and Finance \\ Riga, Latvia \\ elita.liela@ba.lv
}

Abstract - During the last decade software developers have put increasing focus on developing information systems supporting decision making, collaboration, knowledge and idea management. Idea management systems (IMS) - manageable systematic tools to generate and evaluate ideas - are an important element within this trend. Webbased IMS are used by many well-known organizations, e.g. Volkswagen, Cisco, Microsoft, Lidl, GE Healthcare, Nestle, Procter and Gamble, Tchibo, Henkel, Roche, Fujitsu, Boeing, Goodyear, Xerox, Panasonic, Pentax, Siemens, Virgin trains etc. Although the research on web-based IMS and how these systems are applied practically is very limited. Therefore, the authors of this research aim to explore practical webbased IMS application and potential benefits. Research aim is based on theoretical and empirical approaches to deliver understanding on how web- based IMS materializes and what are potential benefits from its application to increase organizational effectiveness. Web-based IMS application will be researched by analysing separate use-cases and reprocessing the results using content analysis. 1st step analysis of 100 users cases based on available information about application cases from homepages of web-based IMS developers. 2nd step -analysis of the results from 1st step. The analysis will be conducted by analysing information from protocols of use-cases. Protocols will be organized as category maps. Category maps are based on literature studies (finding deductive elements with available data), on data (inductive elements) and organized around Adaptive Structuration Theory elements. As the 3rd step use case descriptions and comparison will be applied. The results show that the web-based IMS are universally applicable in different organisation for fulfilling the various tasks. Benefits of web-based IMS application could be divided into 4 main groups towards benefits of- the idea management, innovation management, cooperation, and overall effectiveness of organization. Academic contribution: (1) most extensive research of web-based IMS based on 100 use cases; (2) empirical overview of potential benefits of web-based IMS application; (3) Development of IMS use case analysis protocol applicable in further researches. Practical contribution: (1) Empirical overview of webbased IMS application experience in various organizations that can stimulate the application of web-based IMS in other organizations and to deliver benefits to organization; (2) The benefits are summarized and can help in decision making whether to apply and implement a web- based IMS in and an organization.

Keywords-Benefits, Idea Management Systems, Organisational Effectiveness.

\section{INTRODUCTION}

IT application and information management in organizations have become as crucial as ever for matching 3 major trends- (1) in the age of innovation economy tools that provide means for acquiring, evaluation and development of knowledge and ideas are extremely important; (2) the growing role of ICT increases the importance of web-based tools that allow to support innovation process; (3) web-based IMS are becoming more important in the context of open innovation and coinnovation, giving the access to both internal and external sources of ideas and knowledge.

There is a main literature gap on providing answers to the questions how web-based IMS metalizes within organisations and what are the potential benefits from web-based IMS application? See the topicality and gap in Fig. 1.

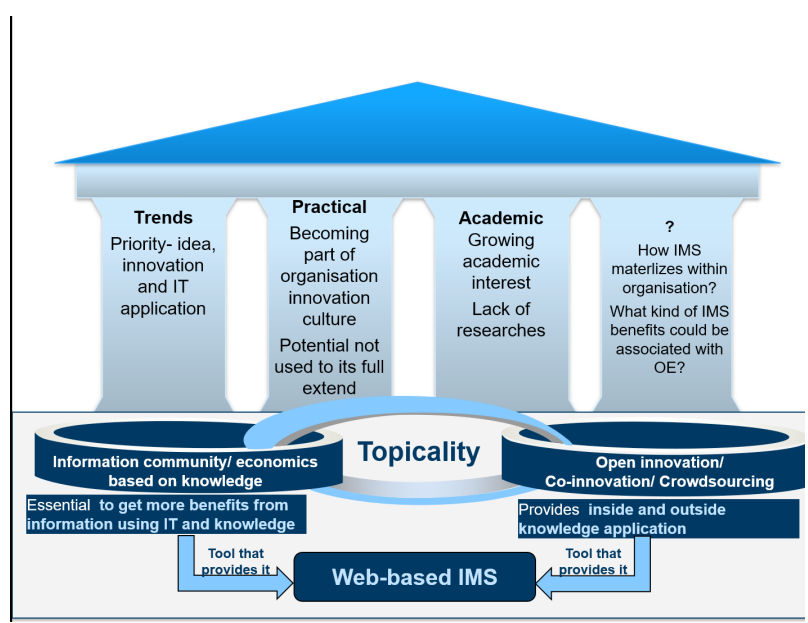

Fig. 1. Research topicality and gap.

Organisational effectiveness (OE) is a one of the main topics in management science [1], [2], and in recent 
decades topicality of OE research has grown rapidly [3], [4]. Idea management (IM) as a separate research topic emerged and became very topical from 2002 focusing mainly on IM application and problems, but also about practical increase of web-based IMS application [5].

Research aim - based on theoretical and empirical approaches to deliver understanding on how web-based IMS materializes and what are potential benefits from web-based IMS application to increase organizational effectiveness.

To reach the research aim case studies were selected as the data selection method, but for data analysis - content analysis. In section II more information about methods and materials.

\section{Materials And Methods}

\section{A. Definitions and basics}

Idea management (IM) is a process of idea generation, evaluation, and continuation. Idea management system (IMS) is a tool, tool kit or complex system which provides systematic, manageable process of idea generation, evaluation and continuation [5], [6]. In this research authors concentrates on IMS research stream that research existing IMS not creation of new systems [7]- [9].

Adaptive structuration theory (AST) which argues that the effects of ICT on outcomes depend on the ICT structures and on the adaptive structures that forms when members apply ICT [10).

Organizational effectiveness (OE) - multidimensional measurement which could consist from financial / nonfinancial, internal/external, subjective and objective dimensions, which reflects achievements of the organization towards the goals set[11].

\section{B. Methodology}

Web-based IMS application researched by analysing separate case studies and reprocessing the results using content analysis (see in Table I).

TABle I. Data Selection and Analysis

\begin{tabular}{|c|c|}
\hline Section & Description \\
\hline Data Selection & $\begin{array}{l}\text { Case analysis. Justification - to analyze cases of web- } \\
\text { based IMS application. }\end{array}$ \\
\hline Data Analysis & $\begin{array}{l}\text { Constant analysis. Justification- to compare } \\
\text { application cases and explore benefits of web-based } \\
\text { IMS application, that could be associated with OE. }\end{array}$ \\
\hline Time Period & $2010-2017$ \\
\hline $\begin{array}{l}\text { Method } \\
\text { Application } \\
\text { Steps }\end{array}$ & $\begin{array}{l}\text { 1.Creation of case study protocol. } \\
\text { 2.Case study documents based on information } \\
\text { available on } 108 \text { web-based IMS websites (selected } \\
\text { in previous author's research) and individual } \\
\text { communication with the purpose of obtaining } \\
\text { additional information. Selection of } 100 \text { cases } \\
\text { with most information available for our case study } \\
\text { protocols. } \\
\text { 3.Content analysis of the obtained materials. } \\
\text { Creating and comparing case descriptions. }\end{array}$ \\
\hline
\end{tabular}

Data selection method: 100 case studies based on application cases published by web-based IMS developers and available information about the applications cases from homepages of web-based IMS developers. Data analysis method: content analysis of protocols from case studies. Protocols are organized as category maps (see in Table II).

TABLE II. CATEGORY MAP

\begin{tabular}{|c|c|}
\hline $\begin{array}{l}\text { Organizational } \\
\text { category }\end{array}$ & Basic category \\
\hline \multirow{2}{*}{ Web-based IMS } & Product name \\
\hline & Application aim \\
\hline \multirow{8}{*}{$\begin{array}{l}\text { Organizational } \\
\text { system }\end{array}$} & Organization using the product \\
\hline & Organization size \\
\hline & Country \\
\hline & Previous experience with IMS (yes/no) \\
\hline & Moderation of IMS (automatic, manual, mixed) \\
\hline & Geographical area \\
\hline & Number of persons participating in IM \\
\hline & Who owns the ideas \\
\hline \multirow{8}{*}{$\begin{array}{l}\text { Other structural } \\
\text { sources - tasks }\end{array}$} & Task \\
\hline & Time period \\
\hline & $\begin{array}{l}\text { IMS application time (internal IM, external IM, } \\
\text { mixed IM) }\end{array}$ \\
\hline & Persons participating in IM \\
\hline & Active/ passive IM \\
\hline & $\begin{array}{l}\text { Ideas created for improving product/ process/ } \\
\text { organizational/ marketing }\end{array}$ \\
\hline & Usable for solo or group idea generation sessions \\
\hline & Rewards for best ideas (yes/no) \\
\hline \multirow{3}{*}{$\begin{array}{c}\text { Direct results from } \\
\text { IMS }\end{array}$} & Quantity of ideas \\
\hline & Quality of ideas (how many ideas are developed) \\
\hline & Participation (how many participants) \\
\hline IMS application & IMS application is in accordance to IMS type \\
\hline \multirow{3}{*}{ End results } & Did application achieve its aim? \\
\hline & Are there any other results? \\
\hline & Were new structures created? \\
\hline
\end{tabular}

The analysis was conducted by analysing information from protocols of case studies which are organized as category maps.

Category maps are based on literature studies (finding deductive elements with available data), on data (inductive elements) and organized around Adaptive Structuration Theory elements. The case study descriptions and comparison were applied to analyse.

Main research questions: (RQ1) How web-based IMS materialize within organisations? (RQ 2) What are the main web-based IMS benefits that could be linked with OE?

\section{Results AND Discussion}

Research gives insight in practical application cases of web-based IMS and empirically highlights potential benefits from web-based IMS application. Research shows that web-based IMS are applied in wide variety of wellknown organizations, e.g. Volkswagen, Cisco, Microsoft, Lidl, GE Healthcare, Nestle, Procter and Gamble, Tchibo, Henkel, Roche, Fujitsu, Boeing, Goodyear, Xerox, 
Panasonic, Pentax, Siemens, Virgin trains.

Case studies are mostly from large organizations. Unfortunately, information about web-based IMS application in small organizations is sparse. 100 use cases are collected from both service providers and manufacturers from various industries and regions. 48 of companies reviewed didn't have any previous experience with web-based IMS application. Beneficial application cases by enterprises show that web-based IMS are easily adaptable for businesses.

Web-based IMS are used both locally and transnationally with positive results on involvement, idea quality and quantity. It is worth noting the fact that multinational companies use systems mostly for internal IM, but in very rare cases for international mixed or external ideas management. In all application cases webbased IMS are moderated both manually and automatically and all rights to ideas are owned by companies.

Web-based IMS are towards idea development from various spheres (marketing, product development, process improvements, organizational improvements). Most often ideas are generated for creating new products. This indicates the universality of the usability of the web-based IMS. Web-based IMS are flexible in terms application timeframe as there are companies that use IMS for multiple years and companies that apply IMS for separate occasions, sometimes just for few days. Whether the duration of the use experience is correlated with the results of the IMS, the authors will study in next paper.

Web-based IMS are mostly used for active internal or external IM, and mixed application cases are few. Employees, clients, general public and experts are most common groups participating in idea generation according to reviewed cases. It is rare for the web-based IMS to be adapted for specific expertise and knowledge of participating groups (e.g. Employees generate ideas and clients evaluate). Comparing the size of the network with the extent of involvement, it can be concluded that companies have the potential to increase the volume of creators / evaluators involvement, as the size of the network is much higher than the actual volume of involvement.

By examining the type of web-based IMS, it can be concluded from the pre-established classification, compared to practical use, that all systems are used according to the type of web-based IMS, e.g. The conclusion corresponds with idea found in AST system structures have to be applied in accordance to its characteristics and aims to achieve better results.

The main results of the application of web-based IMS are the quality of ideas, quantity of ideas and involvement of creators / evaluators - provide an additional basis for studying the implications of results, as the results of the web-based IMS are different in case studies. For example, the involvement of large employees as creators of ideas / assessors results in a high quantity and quality of ideas. It verifies the practical significance of theoretical research questions. If we look at the formation of new structures, they are mostly related to the integration of the webbased IMS into the activities of a particular company (mostly in innovation and project management), which in turn determines the formation of new rules. Intellectual resources, such as patents, idea databases, etc., are created as a new structure. This conclusion verifies the research question put forward and justifies the choice to explore how the use of web-based IMS affects not only OE but also the formation of new structures as determined by AST.

The results of the study show that web-based IMS can be used to achieve different goals with diverse benefits that support theoretically derived conclusions and 100 results of web-based IMS research. Study proposes to categorize benefits of web-based IMS application such as an innovation management benefits, ideas management benefits, cooperation benefits and overall benefits of organization.

The use of web-based IMS for companies can results in IM benefits. For example, in two years, Citrix (USA) used IdeaScale web-based IMS to improve the IM process for both internal and external IM, involving 2,000 employees and customers, who generated a total of 1,800 ideas [12]. In turn, Amer Sports (Finland), using web-based IMS Qmarkets, with the aim of improving the IM process, also led to increased employee engagement in the innovation process, that is, out of 8,500 employees in IM years, 4250 were involved [13].

Innovation benefits are often mentioned as the main purpose for using web-based IMS. For example, in order to improve innovation management, Virgin Trains (UK) used web-based IMS Sideways 6, involving 7,000 employees who created ideas to improve innovation management. As a result, various innovations were introduced, employee engagement increased, and IM became easier [14]. The Avios (UK) used the same web-based IMS to promote creative ideas and created an environmental object in the Light the bulb campaign that lights up when someone submits an idea. 400 employees took part in presenting 300 ideas. The company concluded that process IM has been improved by engaging more employees [15] (see in Table III). 
TABLE III. Benefits ASSOCiated with OE

\begin{tabular}{|c|c|c|}
\hline & In more than $50 \%$ of cases & $\begin{array}{l}\text { In less than of } \\
50 \% \text { case }\end{array}$ \\
\hline$\Sigma$ & $\begin{array}{l}\text { Identify and develop new ideas. } \\
\text { Idea storage. } \\
\text { Structured and controlled IM. } \\
\text { Improved IM processes. } \\
\text { IM economize time } \\
\text { IM without geographic and time barriers } \\
\text { IM without barriers for involvement }\end{array}$ & - \\
\hline 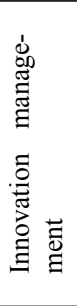 & $\begin{array}{l}\text { Implementation of ideas } \\
\text { Motivate innovation culture } \\
\text { Higher creativity } \\
\text { Speed up current innovation management } \\
\text { process } \\
\text { Increased innovation potential } \\
\text { Provide ideas for new products } \\
\text { Provide ideas for new processes } \\
\text { Provide ideas for marketing Provide organi- } \\
\text { zational improvements } \\
\text { Support for open innovations }\end{array}$ & $\begin{array}{l}\text { Greater freedom that } \\
\text { creates better innova- } \\
\text { tion habits. Improved } \\
\text { innovation capacity. } \\
\text { Decreased risks in } \\
\text { Idea implementation } \\
\text { process. Ability to } \\
\text { identify employees } \\
\text { that are ready to be- } \\
\text { come main innova- } \\
\text { tors }\end{array}$ \\
\hline & $\begin{array}{l}\text { Co -creation opportunities } \\
\text { Improvements in previous cooperation } \\
\text { Improvements in external cooperation in IM } \\
\text { processes } \\
\text { Increase in participation } \\
\text { Team work } \\
\text { Motivation of the involved persons } \\
\text { Networking } \\
\text { Satisfaction with work } \\
\text { Improved relationships in the company } \\
\text { Strengthening of trust }\end{array}$ & $\begin{array}{l}\text { Expand the number } \\
\text { of involved persons } \\
\text { in knowledge ap- } \\
\text { plication. Fast and } \\
\text { effective reaction to } \\
\text { problems. } \\
\text { Develop community } \\
\text { and strengthen trust. } \\
\text { Improve team pro- } \\
\text { ductivity. }\end{array}$ \\
\hline 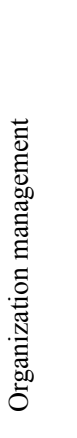 & $\begin{array}{l}\text { Effective decision making } \\
\text { Improvements in information manage- } \\
\text { ment } \\
\text { Management effectiveness } \\
\text { Growth of the company } \\
\text { Improved quality, client satisfaction, } \\
\text { financial indicators. } \\
\text { Aims achieved } \\
\text { Defining aims } \\
\text { Introduction of new products in the } \\
\text { market } \\
\text { Larger market share } \\
\text { Ability to react to changes }\end{array}$ & $\begin{array}{l}\text { Competitive advan- } \\
\text { tage over compet- } \\
\text { itors. Establishing } \\
\text { new structures, IMS } \\
\text { are integrated in or- } \\
\text { ganization's system, } \\
\text { processes. }\end{array}$ \\
\hline
\end{tabular}

Cooperation as a goal and benefit in the use of webbased IMS appears very often, characterized by co-operative opportunities, improvement of internal co-operation, improvement of external co-operation, increase of involvement, teamwork, motivation of stakeholders, networking, satisfaction with work, strengthening of relationship in the company, strengthening of trust. Many companies only involve their employees in the use of web-based IMS, for example, the international company Autoliv - a manufacturer of security solutions for cars, has used IIS BrightIdea to create solutions for various innovationrelated issues and to introduce an open innovation approach. In one year, 6000 people were involved, mostly engineers, creating 1584 ideas, $99 \%$ of which were introduced. As a result, the innovation team grew by $800 \%$ [16]. Employee Y increased the motivation of the employees by engaging them in the development of the company and promoting innovation as the goal of the company using web-based IMS Ezassi and reaching $96 \%$ of employees within one year. The company admits that $56 \%$ of ideas were used and developed [17]. Since 2005, Zebra Technologies has set the task of motivating employees through web-based IMS Imaginatik involving 2,500 employees. The use of web-based IMS was integrated into the company's innovation culture, for example, in order to motivate employees IM, the most active participants are given innovatory stripes (zebras of innovation), which confirm involvement in IM [18].

Earlier cases included general management effectiveness indicators related to decision making, financial results, etc., but there are several instances of the use of web-based IMS highlighting the direct and indirect impact of the use of web-based IMS on overall organization benefits indicators. For example, the use of Fujitsu Emeia web-based IMS Hype has resulted in an income of 25 million euros, integrating web-based IMS into project management methodology and involving 156,000 employees over 18 months [19]. In turn, the webbased IMS Idea Spotlight saving 100,000 pounds a year helped Waitrose (UK), which already involved 60000 employees for the first 6 months and gained 2100 ideas, of which 124 were introduced, but the company concluded that $50 \%$ of all ideas were with development potential [20]. Using the web-based IMS IdesScale for one year, Kane (USA), with the involvement of 1,000 employees, created ideas that resulted in 1\% financial savings [21].

\section{CONCLUSIONS}

\section{A. Summary}

Research shows that web-based IMS are applied in wide variety of organizations both of service providers and manufacturers from various industries and regions. Web-based IMS are used both locally and international with positive result. Web-based IMS are applied to tasks from various spheres (marketing, product development, process improvements, organizational improvements). Web-based IMS are mostly used for active internal or external IM, and mixed application cases are few. Employees, clients, general public and experts are most common groups participating in idea generation according to reviewed web-based IMS application cases. The conclusion corresponds with idea found in AST - system structures have to be applied in accordance to its characteristics aims to achieve better results. Study proposes to categorize benefits of web-based IMS application - innovation management benefits, ideas management benefits, cooperation benefits and overall benefits of organization.

\section{B. Contribution and Further Researches}

Theoretical contribution: (1) paper fulfils an identified need to clarify web-based IMS concept applying theoretical and empirical approaches; (2) it is the widest webbased IMS empirical research based on 100 case studies; (3) indicated benefits that could be associated with OE; (4) web-based IMS case study analysis protocol is applicable in further researches. Practical contribution: (1) empirical and analytic summary of web-based IMS application cases in various organizations that can be studied and adapted by other organizations; (2) evaluation of benefits and limitations of web-based IMS is applicable in decision making process in organizations when approaching web-based IMS application. Further research directions: (1) How organisations adapt/customize systems to their 
own use and implement it in their operations? (2) How different classes of web-based IMS impact organisation results? That also collides with van den Ende et. al. [22] call.

\section{REFERENCES}

[1] P.S. Goodman and A.M. Saks, New Perspectives on Organizational Effectiveness, San Francisko: Jossey - Bass, 1977.

[2] S. Biswas, "Relationship between psychological climate and turnover intentions and its impact on organisational effectiveness: A study in Indian organisations," IIMB Management Review, vol.22, pp.102-110, 2010. DOI: 10.1016/j.iimb.2010.04.013.

[3] C. Mausolff and J. Spence, "Performance measurement and program effectiveness: a structural equation modeling approach," International Journal of Public Administration, vol.31 (6), pp.595615, 2008. DOI: 10.1080/01900690701640929.

[4] J.D. Lecy, H.P. Scmitz and H. Swedlund, "Non-govermental and not-for-profit organizational effectiveness: a modern synthesis," Voluntantas: International Journal of Voluntary and Nonprofit Organizations, vol. 23 (2), pp. 434-457, 2012. DOI: 10.1007/s11266011-9204-6.

[5] E. Mikelsone and E. Lielā, "Discussion on the Terms of Idea Management and Idea Management Systems," Journal of Regional Formation and Development Studies, vol. 3(17), pp.97-110, 2015.

[6] S. Gerlach and A.Brem, "Idea management revisited: A review of the literature and guide for implementation, " International Journal of Innovation Studies, vol 1 (2), pp. 144-161, 2017. DOI: 10.1016/j.ijis.2017.10.004.

[7] A. Westerski, T.Dalamagas and C.A. Iglesias, "Classifying and comparing community innovation in Idea Management Systems," Decision Support Systems, vol.54(1), pp.1316-1326, 2013. DOI: 10.1016/j.dss.2012.12.004.

[8] A.R. Sandriev and O.V. Pratchenko, "Idea management in the system of innovative management, "Mediterranean Journal of Social Sciences, vol.5(12), pp.155-158, 2014. DOI: 10.5901/mjss.2014. v5n12p155.

[9] M.Beretta, "Idea Selection in Web-Enabled Ideation Systems," The Journal of Product Innovation Management, vol.36(1), pp. 5-23, 2019. DOI: 10.1111/jpim.12439.
[10] M.S. Poole, “Adaptive Structuration Theory," in Encyclopedia of Management Theory, Ed. E.H. Hessler, Pace University: SAGE Publications, Inc., 2013, pp.22-25.

[11] E. Mikelsone, and E. Liela, "Idea Management and Organizational Effectiveness: Research Gap," Journal of Business Management, vol. 12(1), pp.4-24, 2016.

[12] IdeaScale, "Case Study: Citrix," 2018. [Online]. Available: https:// ideascale.com/casestudy/citrix/ [Accessed: Dec. 17, 2018].

[13] Qmarket, "Case study: Amer Sports," 2018. [Online]. Available: https://www.qmarkets.net/blog/qmarkets-amer-sports-innovative-partnership-created-unprecedented-employee-engagement/ [Accessed: Dec. 17, 2018].

[14] Sideways 6, "Virgin Trains," 2018. [Online]. Available: https:// fast.wistia.com/embed/medias/6705a0nxg7 [Accessed: Dec. 17, 2018].

[15] Sideways 6, "The Avios," 2018. [Online]. Available: https://fast. wistia.com/embed/medias/uc1pq9clit [Accessed: Dec. 17, 2018].

[16] BrightIdea, "Autoliv Case Study, " $2017 . \quad$ [ O n 1 i n e ] . Available: https://www.brightidea.com/customers/autoliv-saving-lives-through-innovation/ [Accessed: Dec. 17, 2018].

[17] e-Zassi, "Innovation Software Case Study: Creating a Culture of Innovation," 2018. [Online]. Available: https://ezassi.com/culture-of-innovation-using-innovation-software-case-study/ [Accessed: Dec. 17, 2018].

[18] Imaginatik, "Case studies," 2018. [Online]. Available: https:// www.imaginatik.com/innovation-management-case-studies/ [Accessed: Dec. 17, 2018].

[19] Hype, "Fujitsu Case Study," 2018. [Online]. Available: https://i. hypeinnovation.com/clients/fujitsu [Accessed: Dec. 17, 2018].

[20] Wozoku, "Case Study Waitrose," 2018. [Online]. Available: https://www.wazoku.com/case-study-waitrose/ [Accessed: Dec. 17, 2018].

[21] IdeaScale, “Case Study: Kane,” 2018. [Online]. Available: https:// ideascale.com/casestudy/kane/ [Accessed: Dec. 17, 2018].

[22] J. van den Ende, L. Frederiksen and A. Prencipe, "The front end of innovation: Organizing search for ideas," Journal of Product Innovation Management, vol.32(4), pp.482-487, 2015. DOI: 10.1111/jpim.12213. 